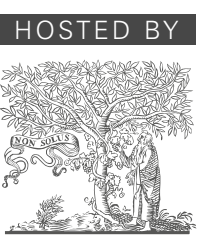

\title{
Implementation of childhood obesity identification and prevention strategies in primary care: A quality improvement project
}

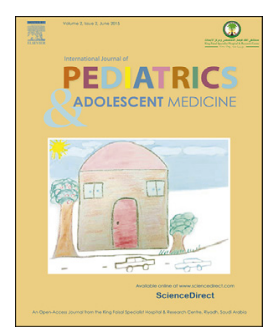

\author{
Audra Rankin ${ }^{a, b, *}$, Jane Blood-Siegfried ${ }^{a}$, \\ Allison Vorderstrasse ${ }^{a}$, Diane Orr Chlebowy ${ }^{b}$
}

\author{
a Duke University School of Nursing, DUMC 3322, 307 Trent Drive, Durham, NC 27710, United States \\ b University of Louisville, School of Nursing, Health Sciences Campus, K-Wing, 555 South Floyd Street, \\ Louisville, KY 40202, United States
}

Received 22 December 2014; received in revised form 28 April 2015; accepted 1 May 2015

Available online 28 May 2015

\section{KEYWORDS \\ Childhood obesity; Motivational interviewing; Quality improvement; Pediatric primary care}

\begin{abstract}
The high incidence and prevalence of childhood obesity, coupled with significant morbidity and financial burden, clearly suggest the need for identification and implementation of effective pediatric obesity prevention strategies in primary care. A solution to this problem includes evidence based clinical guidelines that provide concise, culturally appropriate information on the identification and prevention of childhood obesity in primary care settings. The objective of this quality improvement project was to implement childhood obesity identification and prevention guidelines from evidence-based recommendations into practice. Guidelines were implemented during preventative care visits through the use of a tracking form. The development of the tracking form included input from practice staff resulting in increased fidelity. The tracking form included directions for clear and concise guideline implementation and provided opportunities to record patient BMI, nutritional intake, physical activity, familial obesity prevention education and motivational interviewing and facilitated a practice increase in childhood obesity identification and education. Presence of chart indicators, including nutrition and exercise history, were analyzed to determine the fidelity of the practice change in obesity identification and prevention education. Key outcomes included a significant $(p<.0001)$ practice increase in childhood obesity identification as well as a significant increase $(p<.05)$ in documentation of obesity prevention education through motivational interviewing. Practice change incorporating childhood obesity identification and familial prevention guidelines had positive effects in a pediatric population. Implementation of evidence-based
\end{abstract}

\footnotetext{
* Corresponding author. University of Louisville, School of Nursing, Health Sciences Campus, K-Wing, 555 South Floyd Street, Louisville, KY 40202, United States.

E-mail address: audra.rankin@louisville.edu (A. Rankin).

Peer review under responsibility of King Faisal Specialist Hospital \& Research Centre (General Organization), Saudi Arabia.
} 
guidelines can result in increased identification of children at risk for childhood obesity and enhanced familial obesity prevention education; leading to the long-term goal of creating healthier lifestyles and decreasing risk factors in a vulnerable population.

Copyright (c) 2015, King Faisal Specialist Hospital \& Research Centre (General Organization), Saudi Arabia. Production and hosting by Elsevier B.V. This is an open access article under the CC BY-NC-ND license (http://creativecommons.org/licenses/by-nc-nd/4.0/).

\section{Introduction}

Current research indicates childhood obesity is increasing at an alarming rate in the United States. The increased incidence and prevalence, coupled with significant morbidity and financial burden, clearly suggest the need for implementation of effective pediatric obesity identification and prevention strategies. The National Health and Nutrition Examination Survey (NHANES), 1999-2004, with a sample size of 12,384 American children 2-19 years of age, found that almost $16 \%$ of children were obese. NHANES data showed obesity in children correlated with high morbidity that continued into adulthood including increased cardiovascular risks of elevated cholesterol and abnormally high blood pressure [1]. Obesity predisposes children to poorer pulmonary function, asthma, orthopedic problems, sleep apnea, polycystic ovary disease, and poor psychosocial health related to obesity-associated bullying and discrimination [2].

The National Association of Pediatric Nurse Practitioners developed Healthy Eating and Activity Together (HEAT), evidence-based clinical guidelines that provide concise, culturally appropriate information on the identification and prevention of childhood obesity in primary care settings [3]. The major objectives of the guidelines are to increase healthcare provider effectiveness in identifying children at risk for obesity and encourage optimal eating and activity practices in families. Noteworthy characteristics of the HEAT approach include a focus on prevention and cultural appropriateness. Emphasis is placed on identifying strengths within the family and fostering strong relationships between parents, children, and healthcare professionals. Motivational interviewing is the cornerstone of HEAT guidelines and provides an evidence-based approach for encouraging patients and their families to make healthy lifestyle behavioral modifications [3].

Motivational interviewing (MI) is directive, patientcentered counseling that is designed to be nonjudgmental, empathetic, and encouraging. The technique elicits intrinsic motivation for behavior change and is effective in individuals who are initially resistant to change [4]. The basic premise of the technique is to facilitate an awareness of discrepancies between the patient's current lifestyle and future goals [5]. For example, if a patient wants to play soccer in the fall, but it has no plans for physical activity in the summer, Ml techniques would encourage the patient to identify the discrepancies between his future goals and current lifestyle and make appropriate behavioral modifications. The positive effect of Ml techniques on childhood obesity is consistent with the literature. Evidence illustrates an improvement in healthy lifestyle decisions when $\mathrm{Ml}$ is introduced and maintained in a clinical setting to promote behavioral modification [6].

\section{The local problem}

Kentucky has one of the highest childhood obesity prevalence rankings which places a significant burden on healthcare systems [7]. Unfortunately, there is limited time in the context of routine pediatric primary care visits for healthcare providers to focus on childhood obesity.

Research suggests that socioeconomically disadvantaged children, particularly those of Hispanic and African American ethnicity, are at increased risk for childhood obesity [2]. Demographic characteristics of patients in a local pediatric practice in Kentucky reflected a high proportion from this underserved, high-risk patient population. The Kentucky Cabinet for Health and Family Services reported $16 \%-23 \%$ of children in the local community were significantly obese, with a BMI greater than the 95th percentile [8]. These findings ultimately solidified the need to implement effective pediatric obesity identification and prevention strategies including the use of $\mathrm{Ml}$ to facilitate lifestyle behavior modifications. Project aims included enhancing the consistency of childhood obesity identification and prevention within the clinic population as evidenced by identification of obesity risk factors and increased family focused education through the use of a tracking tool based on current evidence. The purpose was to determine if the use of a tracking tool, based on current evidence based guidelines emphasizing MI would significantly increase childhood obesity identification and documentation of education strategies implemented by healthcare professionals in a primary care setting.

\section{Patients and methods}

\subsection{Scope of the project}

The practice project involved quality improvement of childhood obesity identification and education within the practice and did not include research interventions that affected participants' well-being. IRB approval was obtained through the Duke University Institutional Review Board.

\subsection{Setting}

The practice setting was a pediatric primary care office serving rural and semi-rural communities. Practice staff included a physician, nurse practitioner and physician 
assistant as well as medical assistants and front office staff. The patients ranged in age from four years to young adulthood. The population represented a large underserved minority group; $42 \%$ of the patients received Medicaid benefits and 33\% of those patients identified were Hispanic.

\subsection{Planning the intervention}

Stakeholders and change agents were identified within the practice. The barrier for adopters was having little prior knowledge of effective obesity prevention strategies. As a result, multiple educational sessions occurred at the outset of the project to familiarize the staff with clinical guidelines. Training strategies include education on Ml techniques such as open-ended questions, reflective listening, and assessing patient's interest and confidence levels [4]. Implementation was broken down into smaller steps: measurement, education, documentation and referrals. The Plan Do Study Act model guided practice changes and outcome measures [9].

Providers had frequent contact with one another making increased communication feasible. The practice change was not mandated, but it was implemented using the principles of change theory.

1. Communication: Communication with practice staff occurred on numerous occasions. Staff acknowledged growing childhood obesity rates within the practice and verbally committed to making changes to address the problem. Education on HEAT guidelines and MI strategies was provided through informal and formal communication.

2. Taskforce Development: Following communication with staff, a taskforce of providers and nurses was created to develop a user-friendly "Get Healthy! Tracking Tool" (Fig. 1). The tool was used during annual physical examinations and became a part of the patient chart. This data form was used to document important quality indicators including anthropometric measurements, nutritional and physical activity history, motivational interviewing, referral to appropriate community resources, and follow-up.
3. Implementation: At each physical examination visit, staff nurses collected patient anthropometric data and nutritional and physical activity history. The nurses included the Tracking Tool in the patient's chart and practice providers committed to using the tracking form during physical examinations. The tool served as a reference guide to education and motivational interviewing strategies as well as community resources.

Using MI techniques, appropriate evidence based strategies that encouraged behavioral modification important for obesity prevention were negotiated with the patient and family. For example, during an office visit, a provider had the opportunity to encourage the patient and family to choose an issue regarding the child's diet or physical activity that they would like to change thereby facilitating behavioral modification. Documentation of this agendasetting technique provides an opportunity to explore the patient's work towards the goal at subsequent office visits [10]. Referral education included appropriate knowledge of applicable community resources such as pedometer programs, physical activity opportunities at local community parks, sporting events, and school programs. In addition, information on local gardens and farmers markets was provided to encourage healthy eating habits.

A clinic staff member reviewed all well-child patient encounters between October 2010 and January 2011 and collected study indicators on those with a diagnosis of overweight or obesity, or where there was mention in the chart of any intervention related to weight reduction and diet. These data were compared with data from the tracking tool found in the medical records of all patients who had a well-child visit after its implementation in October 2011-January 2012. Patient identifiers were removed from the tracking tools and saved in a secure file until the end of the project.

Fidelity of data collection, implementation, and followup were evaluated through the use of quality indicators including the presence of weight, height, and body mass index calculation within the chart, documentation of appropriate history and assessment, documentation of familial obesity prevention education/MI, and evidence of community referral and follow-up as needed. Data were cleaned and organized in Excel where variables were

MEASUREMENT:

Age:

Current Weight:

Current Height

Current BMI:

(At risk $=85^{\text {tho }} \%$ and $<95^{\text {th }} \%$, Overweight $=>95^{\text {th }} \%$ )

DOCUMENTATION

Patient Review of Systems/Physical Examination:

HEENT: Headache RESP: asthma, apnea, daytime tiredness, wheezing, tonsillar hypertrophy CARDIAC: HTN, dyslipidemia GI: stomach pain after eating, reflux, GU: gynecomastia, premature adrenarche, MUSC: limp, joint pain DERM: acne, acanthosis nigricans PSYCH: teasing, bullying, anxiety, depression,

Nutritional Intake:

What are favorite foods/snacks/drinks?

Physical Activity:

Do you have more than 2 hours of screen time a day (television/computer/video games)?

Figure 1 Excerpt from tracking tool. 
recoded into binomial data. The data were exported to SPSS. Fisher's Exact Test was used to compare pre and post data indicators with significance set at $(P<.05)$.

\section{Results}

Implementing evidence-based guidelines resulted in increased identification of children at risk for childhood obesity and enhanced familial obesity prevention education. Data on fidelity illustrated a significant increase in provider documentation of childhood obesity identification and prevention topics discussed during preventative care examinations. Fig. 2 illustrates the improvement in the consistency of obesity identification and prevention education using motivational interviewing in the primary care setting.

A significant increase $(P<.0001)$ occurred in provider documentation of favorite foods and drinks, school lunch preference, fast food consumption, snacking in front of the television, amount of screen time (Fig. 3), amount of physical activity, sports participation, and neighborhood safety.

A positive provider change in healthy lifestyle community referrals also occurred. Examples of community resources discussed during visits included local farmers markets, neighborhood playgrounds, local parks, and public sports teams (Table 1). Discussion of resources enabled providers to align healthy lifestyle goals explored during
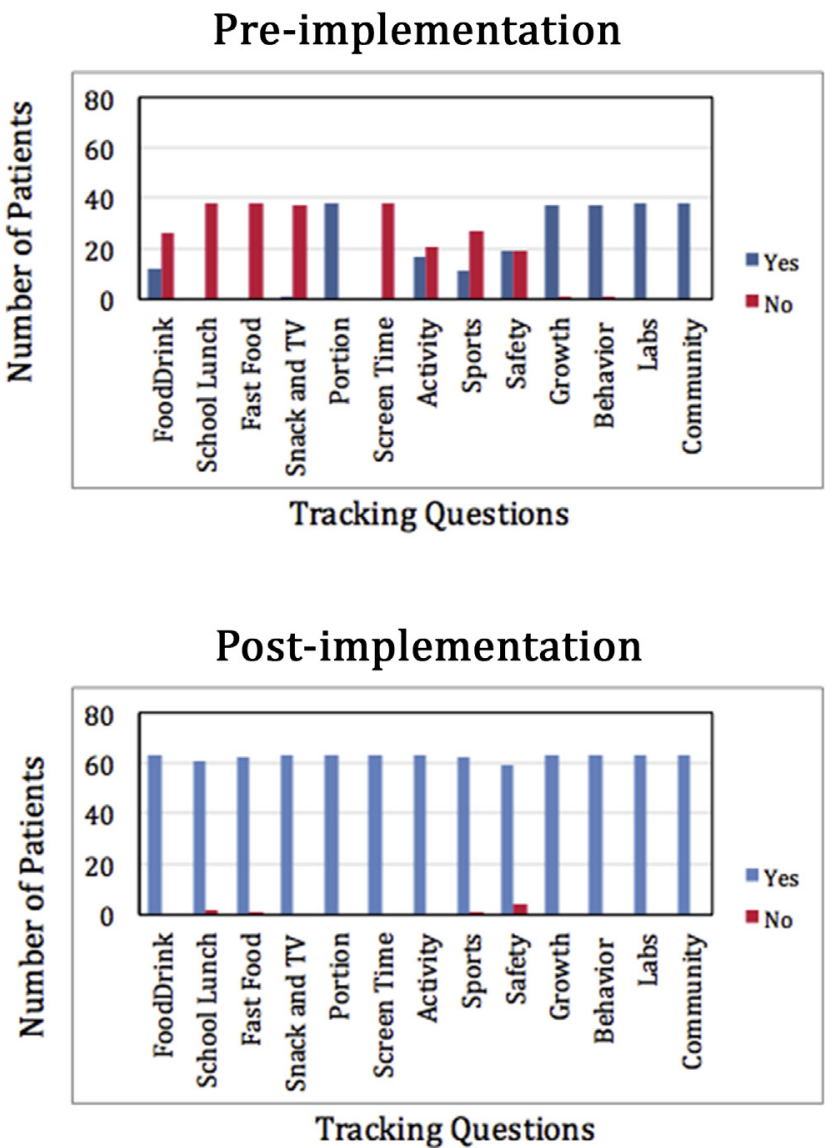

Figure 2 Pre-implementation and post-implementation.

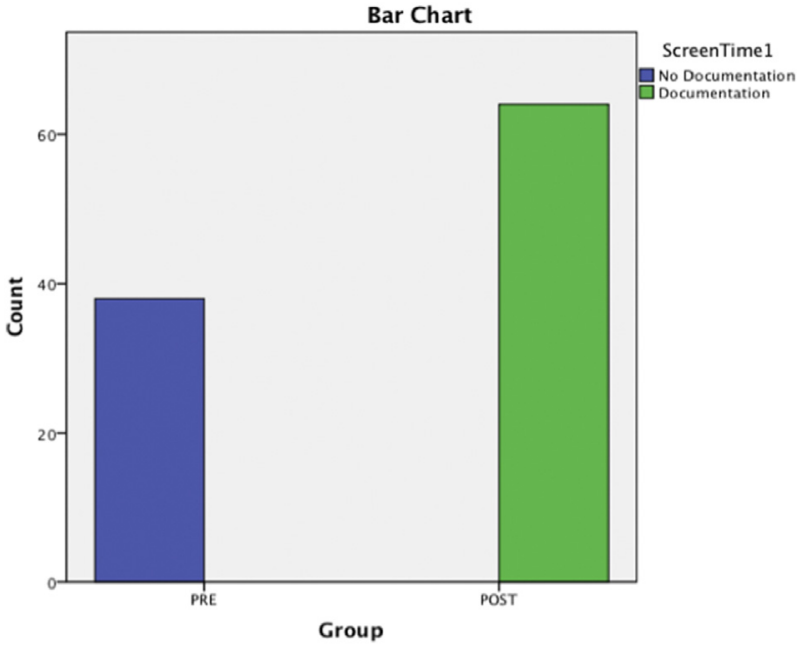

Figure 3 Documentation of Screen Time $>2 \mathrm{~h}$.

preventative examinations with opportunities in the patient's local community and encouraged healthy living options for the entire family. Pre-implementation data illustrated community referrals were rarely documented $(n=1 / 38)$ while post-implementation data showed a positive increase in community referral documentation $(n=47 / 64)$.

\section{Discussion}

In the world of primary care, it is sometimes difficult to incorporate lengthy evidence-based guidelines into practice. Through an innovation model, the practice incorporated the HEAT guidelines by developing a user-friendly tracking tool that had significant staff buy-in, increasing fidelity of use. The tool served as a reminder of childhood obesity during preventative examinations and created a seamless way to follow the progression of individual patients. Prior research clearly suggests the value of lifestyle behavioral modification used as a childhood obesity prevention and intervention strategy [11] and supports implementation of childhood obesity identification and familial education within in pediatric primary care.

This translation of evidence into practice empowered staff to become change agents while enhancing the care provided to pediatric patients. Using the tracking tool significantly improved practice documentation of obesity

Table 1 Community resources.

\begin{tabular}{cll}
\hline \multicolumn{3}{c}{ Community resources: } \\
\hline $\begin{array}{c}\text { Local farmers } \\
\text { market }\end{array}$ & Local parks & Local sports teams \\
$\begin{array}{c}\text { Local farm } \\
\text { stores }\end{array}$ & Public swimming pool & Yoga \& Dance \\
& Classes \\
& $\begin{array}{ll}\text { Community "Healthy } \\
\text { Lifestyle" Events }\end{array}$ & Pedometer program \\
& $\begin{array}{l}\text { Neighborhood } \\
\text { Playgrounds }\end{array}$ \\
\hline
\end{tabular}


identification and therapeutic interventions for pediatric patients resulting in increased awareness of obesity prevention and provision of opportunities to effectively monitor at-risk children. The tracking form served as a successful evidenced based tool for pediatric primary care providers in the practice to empower patients and families to make healthy lifestyle choices through motivational interviewing techniques.

\section{Implications}

The incorporation of $\mathrm{MI}$ on the tracking tool provides an evidence-based approach for encouraging patients and their families to make healthy lifestyle decisions. Although the tool has not been used long enough to indicate a change in patient behavior or clinical outcomes, an increase in provider awareness and education is the beginning step for creating healthier lifestyles and decreasing risk factors in a vulnerable population. Research is needed to evaluate the effects of the evidence based-guidelines on positive behavior change and obesity rates in patients and families.

\section{Sustainability}

Sustainability is important to maintain the clinical gains of increased documentation rather than reverting to old practices. This innovation will require continued revision and improvement in an effort to decrease the likelihood that the innovation becomes an antiquated practice. Through this continual feedback and revision, the innovation will ultimately serve as a catalyst for future changes in childhood obesity identification and prevention education in the primary care practice.

\section{Conflict of interest}

None.

\section{Ethical clearance}

The practice project involved quality improvement of childhood obesity identification and education within the practice and did not include research interventions that affected participants' well-being. IRB approval was obtained through the Duke University Institutional Review Board.

\section{References}

[1] Skelton J, Cook S, Auinger P, Klein J, Barlow S. Prevalence and trends of severe obesity among US children and adolescents. Acad Pediatr 2009;9:322-9.

[2] Oude Luttikhuis $H$, Baur L, Jansen H, Shrewsbury Vanessa A, O'Malley C, Stolk Ronald P, et al. Interventions for treating obesity in children. Cochrane Database Syst Rev (1) 2009. http://dx.doi.org/10.1002/14651858.CD001872. Retrieved http://www.mrw.interscience.wiley.com/cochrane/clsysrev/ articles/CD001872/frame.html.

[3] The National Association of Pediatric Nurse Practitioners (NAPNAP). Healthy eating and activity together (HEAT) clinical practice Guideline: Identifying and preventing overweight in childhood. Cherry Hill, NJ: NAPNAP. Warschburger; 2006.

[4] Schwartz RP, Hamre R, Dietz WH, Wasserman RC, Slora EJ, Myers EF, et al. Office-based motivational interviewing to prevent childhood obesity: a feasibility study. Arch Pediatr Adolesc Med 2007;161(5):495-501. http://dx.doi.org/ 10.1001/archpedi.161.5.495.

[5] Dreyer M, Egan A. Psychosocial functioning and its impact on implementing behavioral interventions for childhood obesity. Prog Pediatr Cardiol 2008;25(2):159-66. http://dx.doi.org/ 10.1016/j.ppedcard.2008.05.007.

[6] Resnicow K, Davis R, Rollnick S. Motivational interviewing for pediatric obesity: conceptual issues and evidence review. J Am Diet Assoc 2006;106(12):2024-33. http://dx.doi.org/ 10.1016/j.jada.2006.09.015.

[7] Singh GK, Kogan MD, van Dyck PC. Changes in state-specific childhood obesity and overweight prevalence in the United States from 2003 to 2007. Arch Pediatr Adolesc Med 2010; 164(7):598-607. http://dx.doi.org/10.1001/archpediatrics. 2010.84.

[8] Kentucky Cabinet for Health and Family Services. Pediatric nutrition surveillance system (PedNSS) 2010 annual report: Comparison by County. 2010. Retrieved on 25.04.12 from, http://chfs.ky.gov/dph/mch/ns/PEDNSS.htm.

[9] Margolis PA, Lannon CM, Stuart JM, Fired BJ, Keyes-Elstein L, Moore DE. Practice-based education to improve delivery systems forprevention in primary care: randomized trial. BMJ 2004, Febrary 6. http://dx.doi.org/10.1136/bmj.38009. 706319.47.

[10] Nyberg G, Sundblom E, Norman A, Elinder L. A healthy school start-Parental support to promote healthy dietary habits and physical activity in children: design and evaluation of a cluster-randomised intervention. BMC Public Health 2011;11(1):185-91. http://dx.doi.org/10.1186/14712458-11-185.

[11] Herrera EA, Johnston CA, Steele RG. A comparison of cognitive and behavioral treatments for pediatric obesity. Children's Health Care 2004;33(2):151-67. 